\title{
Lusioersily
}

\section{Optimising protocols for high-definition imaging of historic shipwrecks using multibeam echosounder}

Westley, K., Plets, R., Quinn, R., McGonigle, C., Sacchetti, F., Dale, M., McNeary, R., \& Clements, A. (2019). Optimising protocols for high-definition imaging of historic shipwrecks using multibeam echosounder. Archaeological and Anthropological Sciences, 11(7), 3629-3645. https://doi.org/10.1007/s12520-019-00831-6

Link to publication record in Ulster University Research Portal

\section{Published in:}

Archaeological and Anthropological Sciences

Publication Status:

Published (in print/issue): 01/07/2019

DOI:

10.1007/s12520-019-00831-6

\section{Document Version}

Author Accepted version

\section{General rights}

Copyright for the publications made accessible via Ulster University's Research Portal is retained by the author(s) and / or other copyright owners and it is a condition of accessing these publications that users recognise and abide by the legal requirements associated with these rights.

\section{Take down policy}

The Research Portal is Ulster University's institutional repository that provides access to Ulster's research outputs. Every effort has been made to ensure that content in the Research Portal does not infringe any person's rights, or applicable UK laws. If you discover content in the Research Portal that you believe breaches copyright or violates any law, please contact pure-support@ulster.ac.uk. 
Optimizing protocols for high-definition imaging of historic shipwrecks using multibeam echosounder

Kieran Westley ${ }^{1 *}$, Ruth Plets ${ }^{1}$, Rory Quinn ${ }^{1}$, Chris McGonigle ${ }^{1}$, Fabio Sacchetti ${ }^{2}$, Mekayla Dale ${ }^{1,2}$, Rory McNeary ${ }^{3}$, Annika Clements ${ }^{4}$

${ }^{1}$ School of Geography \& Environmental Sciences, Ulster University, Coleraine, BT52 1SA, Northern Ireland, UK

${ }^{2}$ Marine Institute, Oranmore, Co. Galway, H91 R673, Rep. of Ireland

${ }^{3}$ Historic Environment Division, Department for Communities, Causeway Exchange, 1-7 Bedford Street, Belfast, BT2 7EG, Northern Ireland, UK

${ }^{4}$ Agri-Food and Biosciences Institute, Fisheries and Aquatic Ecosystems Branch, Newforge Lane, Belfast, BT9 5PX, Northern Ireland, UK

*Corresponding author (kl.westley@ulster.ac.uk; tel: +44 28701 24387), ORCID ID 0000-0002-08636762 


\section{Abstract}

Conservation of historic shipwrecks is prohibitively expensive and in situ preservation and recording is the preferred archaeological approach. Non-destructive high-definition 3D imaging is therefore essential for recording and managing submerged historic shipwrecks. Multibeam echosounders (MBES), the standard tool for hydrographic survey, can produce point clouds to image complex 3D structures. However, wreck imaging is often done using MBES in traditional survey mode optimised for morphological characterisation of the seafloor. This does not necessarily provide high-definition imagery required by archaeologists. This study demonstrates key factors influencing high-definition MBES imaging of wrecks through a controlled field experiment. Results show that optimal highdefinition 3D imaging is achieved through maximising the pulse rate, narrowing the angular sector, using the highest frequency and shortest pulse lengths, applied to at least 3 to 5 overlapping centreline-parallel and offset passes with additional perpendicular/oblique lines. Variations in survey design are demonstrated to exert strong controls on sounding density and distribution, with highdensity on horizontal and vertical wreck surfaces enabled by a combination of overlapping passes and offset lines. Adoption of this method would result in more widespread high-definition 3D imaging of wrecks to benefit archaeological research and develop effective mitigation strategies to minimise loss of the fragile underwater resource.

\section{Keywords}

Multibeam echosounder, shipwreck, marine geoarchaeology, point cloud, high-definition imaging, best practice 


\section{Introduction}

Shipwrecks are recognized for their cultural and archaeological significance, providing empirical evidence of past trade and migration, technological change, and both shipboard and wider society (Adams 2001; Gibbins and Adams 2001; Flatman 2003). In some instances they are monuments to historic events ranging from individual disasters like the sinking of Titanic (Ballard and Archbold 1987) to global conflicts such as the First and Second World Wars (McCartney 2016).

Researching and managing historic shipwrecks are linked by the need for accurate 3D models of both the wrecks and their seabed context. Conservation of wrecks is prohibitively expensive and, when combined with the additional costs involved in the removal and subsequent conservation of contextual information by excavation, means that preservation in situ is the preferred approach (Maarleveld et al. 2013). This necessitates use of non-destructive imaging techniques, which can be used to represent the digitally-preserved record of the wreck and create detailed visualizations for the non-diving public, enhancing awareness of the underwater cultural heritage (Calder et al. 2007; Dean et al. 2007; Eriksson and Rönnby 2012). Imaging of the wreck and surrounding seabed also allows documentation of the wreck structure, and time-lapse surveys allow physical processes acting on sites to be assessed providing insights into the rate and pattern of degradation (Astley et al. 2014; Fernandez-Montblanc et al. 2016; Manders 2009; Mertes et al. 2017; Quinn \& Boland 2010).

Notwithstanding recent advances in Structure-from-Motion photogrammetry (Mertes et al., 2017) and Synthetic Aperture Sonar (Ødegård et al. 2018), multibeam echosounders (MBES) remain the preferred systems for imaging submerged wrecks (e.g. Plets et al. 2011). They are the most common system for general seabed mapping (Hughes Clark 2017; Lecours et al. 2016) and produce dense point clouds suited to imaging complex 3D structures (Calder et al. 2007; Dean et al. 2007). Advances in MBES design, positional accuracy and an increase in computing capability mean that it is now possible to resolve seabed features at centimetric-scale (Hughes Clarke 2017; Mayer 2006). These improvements mean that it is feasible to acquire high-definition (HD) data of historic shipwrecks. We 
define $H D$ as that which goes beyond the minimum-size feature detection threshold specified by the International Hydrographic Organization Special Order (cubic feature $>1 \mathrm{~m}^{3}$ requiring a minimum of 9 soundings to define: IHO 2008). The need for HD imaging in studies of wreck site formation/degradation is arguably essential because sub-optimal imagery could potentially only detect major changes, and miss incremental smaller changes.

HD-imaging requires MBES data to be high-resolution and high-density. Resolution is defined acoustically as the ability to distinguish returning echoes from two closely-spaced objects as two distinct targets (Lurton 2010). High-resolution is therefore essential to ensure that small features (e.g. parts of the wreck structure) can be distinguished. Density refers to the spacing of acquired point data (soundings). High-density (ideally centimetric- to low decimetric-spacing) is needed to resolve small features and allow production of point-based images which do not rely on interpolation - hence risking introduction of data artefacts - to simulate solid surfaces. However, routine use of MBES does not automatically result in HD imaging. Sounding density and resolution are heavily dependent on the MBES hardware, software acquisition settings and survey design (see below and Bates et al. 2007, 2011; Calder et al. 2007; Plets et al. 2013). This is especially true for shipwrecks as they are often surveyed incidentally during wider programmes of hydrographic (e.g. UK Civil Hydrography Programme, Irish INFOMAR Programme), industry or scientific survey (e.g. Bellec et al. 2017; Calvert et al. 2015; Plets et al. 2012; Sacchetti et al. 2012; Strong et al. 2012). For example, in hydrography, acquisition is geared towards morphological characterization of the seafloor and, for shipwrecks, establishing the least depth for navigational safety (Hughes Clarke et al. 2006; 2017). For upstanding wrecks, this can result in incomplete imaging that shows detail of the top of the wreck, but not the hull sides, making it appear to 'float' above the seabed (Fig. 1). However, if the integrity of the entire wreck needs to be investigated (e.g. for management purposes), then knowledge about the entire hull is essential. 
This paper briefly outlines the principles behind MBES data resolution and density. We then demonstrate key factors that influence HD MBES imaging through a controlled field experiment over a historic shipwreck under typical survey conditions. We argue that optimising MBES survey design and settings using the results from these experiments represents an advance in survey methodology and a robust technique for 3D digital recording of archaeological sites underwater.

\section{MBES data resolution and density}

MBES systems comprise a transmitter $\left(T_{x}\right)$ and receiver $\left(R_{x}\right)$ array, with transmitted beams being wide in the across-track but narrow in the along-track direction, and received beams wide in the along-track and narrow in the across-track direction. The intersection of these beams creates a series of small footprints, the size of which determines the resolution of the system (Fig. 2). Alongtrack resolution $(\delta x)$ is given by:

$\delta x=\phi R$,

where $R$ is oblique range and $\phi$ is the beam aperture in the horizontal plane (Lurton, 2010). Acrosstrack resolution $(\delta y)$ is approximated by:

$\delta y=\frac{N v \tau}{2 \sin \theta}$,

where $\theta$ is the beam steering angle (relative to the vertical), $N$ is signal independent samples used in the averaging operation, $v$ is velocity of the acoustic pulse and $\tau$ is pulse length (Lurton, 2010). The value of $N$ depends on the detection algorithm implemented by the manufacturer. Effectively, the combination of $\delta x$ and $\delta y$ produces a footprint whose size increases with distance from the transceiver and with pulse length (Fig. 2; Hughes Clarke 2017).

To maximise sounding density in the along-track direction, the frequency of signal transmission must be as high as possible. The optimal pulse rate $(P R)$ is achieved by transmitting the signal $n+1$ as soon as the signal $n$ is received: 
$\frac{1}{f_{P R}}=\frac{2 H}{v \cos \theta_{\max }}$

where $\theta_{\max }$ is the maximum steering angle of the receiver beams and $H$ is the altitude of the transceiver (Lurton 2010). Increasing along-track data density is achieved by reducing survey platform speed to minimize the spatial distance between pulses. Conversely, density in the acrosstrack direction depends on the total number of beams and the width of the angular sector. More beams increases the number of footprints, while narrowing the angular sector decreases their spacing (Hughes Clarke 2017).

Some parameters are fixed and dependent on the MBES hardware; notably the number of beams (generally $>200$ ) and the detection algorithm. Others are user-selectable, notably $\theta_{\max }, \tau$ and PR. $\phi$ and $\tau$ can also be changed indirectly since they vary with operating frequency, which is userselectable on multi-frequency systems. $R$ and $H$ are controlled by the position of the transceiver relative to the target and can be altered via the survey platform configuration (e.g. hull vs polemount) or survey strategy.

In summary, high-resolution and high-density can be attained using high frequency, short range, narrow angular sector, short pulse length, high pulse rate and slow survey speed. Of these, the most important single factor is range, because it affects both beam footprint size (i.e. resolution) and beam spacing (i.e. density) (Bates et al. 2007; 2011; Hughes-Clarke 2017). Across- and along-track data density can also be increased by overlapping survey passes so that the same target is ensonified multiple times (Bates et al. 2011; Calder et al. 2007). A final consideration is the overall sounding distribution on the target. Resolution and density at any given point are controlled as above, but the shape and orientation of the wreck relative to the transceiver may either impede the transmitted beams or reflect them away from the receiver array, creating acoustic shadows (Fig. 1).

These considerations have led to the development of the 'slow and low' strategy for wreck surveys utilizing bespoke extended pole-mounted or Remotely Operated Vehicle (ROV)-mounted MBES 
systems to get the transceiver close to the target. These systems, initially developed for archaeology and commercial salvage (Bates et al. 2007; 2011; Dean et al. 2007), require a specialized contractor and/or equipment and are therefore financially prohibitive and difficult to integrate within broad seafloor mapping programmes.

\section{Materials and Methods}

\subsection{MBES Setup}

Experimental data were acquired onboard RV Celtic Voyager on 8 September 2015 using a hullmounted single-head Kongsberg EM2040. Weather conditions for the survey were fair with a slight sea state and light wind. Speed over ground was maintained as close to $4 \mathrm{kn}$ (minimum required for the survey vessel to keep a consistent heading) as possible; in practice it varied between $3-5 \mathrm{kn}$ depending on the survey direction and local tidal currents The EM2040 is a multi-frequency MBES $\left(200,300\right.$ and $400 \mathrm{kHz}$ ) with 400 beams divided into three sectors and a total angular sector of $200^{\circ}$ $\left(100^{\circ} / 100^{\circ}\right)$. All or just one sector can be used per pulse (normal versus single sector mode) (Kongsberg 2016). Position fixing was provided by an Integrated GNSS/L-Band receiver CNAV 3050 (horizontal/vertical accuracies of $+/-5 \mathrm{~cm} / 10 \mathrm{~cm}$ ). Motion referencing, secondary positioning and accurate timing were provided by a Seatex Seapath $330+$. Water column sound velocity control used a Valeport Midas SVP profiler and a real-time AML surface sound velocity sensor. Data were logged onboard using Kongsberg Seafloor Information System (SIS) acquisition software. Raw and processed data is currently archived at the Marine Institute under the INFOMAR programmeEmphasis is placed on the use of a conventional hull-mounted setup (as opposed to an ROV- or extended pole-mounted system) to enable more effective and widespread collection of useful HD imagery of wrecks if optimized strategies are integrated into wider programmes of seabed mapping.

\subsection{Controlled experiment}


The controlled experiment was conducted over SS Polwell, a defensively-armed steam collier torpedoed by German submarine U-96 on 5 June 1918. She sank $10 \mathrm{~km}$ northeast of Dublin in $30 \mathrm{~m}$ of water on a sandy seabed (Fig. 3a). Legacy MBES data collected by a standard hydrographic survey showed the wreck as mostly upstanding but broken into three sections (Fig. 3b). The entire wreck measures $92 \mathrm{~m}$ in length from bow to stern, and has a maximum width of $12 \mathrm{~m}$ (Brady et al. 2012). SS Polwell was chosen as the target because she is an upstanding WW1 metal wreck, thus representative of many similar vessels which presently or will shortly fall under the UNESCO (2001) Convention. In some countries, such as the Republic of Ireland, this means that they now fall under statutory protection.

The experiment tested acquisition settings influencing data resolution (frequency/pulse length, bottom detection algorithms) and density (angular sector, pulse rate), and survey design strategies influencing data density and distribution. The impact on resolution was judged qualitatively by visual comparison between small features imaged under different settings while the impact on density was assessed quantitatively using calculated surface density of soundings. Additional factors affecting resolution and density such as hardware capability (number of beams, accuracy of positioning/motion referencing systems), hardware installation (dimensional survey), calibration and sound velocity corrections were not tested as these are standard considerations in hydrographic survey (IHO 2008; 2011; Plets et al. 2013; USACE 2013). Our chosen experimental parameters are those which depart from standard hydrographic practice, and can be modified during survey, to achieve the specific objective of HD shipwreck imaging (see also Bates et al. 2007; 2011). The experiment was divided into testing of acquisition settings and testing of survey design.

\subsubsection{Acquisition settings}

Frequency, pulse rate, angular sector and bottom detection were assessed (Table 1). Frequency was varied between all three transmit options: $200 \mathrm{kHz}, 300 \mathrm{kHz}$ and $400 \mathrm{kHz}$. Angular sector was varied at predefined angles: $20^{\circ} / 20^{\circ}, 30^{\circ} / 30^{\circ}, 40^{\circ} / 40^{\circ}$ and $0^{\circ} / 60^{\circ}$. Based on water depth and angular 
sector, upper pulse rate limits of 4,8 and $12 \mathrm{~Hz}$ were tested. Three bottom detection algorithms were investigated: normal (standard for seabed mapping), minimum depth (returns shallowest depth) and tracking (minimum depth with additional filter to avoid fish returns).

When one setting was tested, all other aforementioned options were kept constant to ensure that only its impact on the acquired data was recorded. Several other user-selectable options were also kept constant throughout. Beam spacing mode was set to 'equidistant' to maintain equal spacing between soundings. Angular coverage mode was set to 'manual' to prevent automatic adjustment of the angular sector in response to depth changes. Pulse length could not be selected precisely, as it co-varies with frequency. The pulse length option was therefore set to Short Continuous Wave (CW); effectively giving the shortest possible pulse length at a given frequency.

All tests were done using pre-defined survey lines offset from the wreck centreline by $25 \mathrm{~m}\left(40^{\circ} / 40^{\circ}\right.$

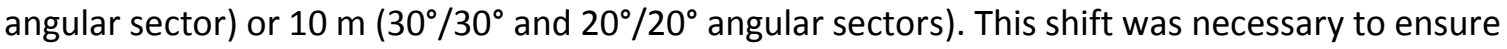
that the wreck fell within the MBES swath when the angular sector was narrowed.

\subsubsection{Survey design}

Survey designs were chosen to test previously published approaches (Calder et al. 2007; MCA 2013; Plets et al. 2013) while comparing the impact of line placement and orientation (Fig. 4):

(a) Single line along wreck centreline: following Calder et al.'s (2007) suggestions for imaging a lowrelief target or a 'beauty pass' to collect high-density data over a wreck.

(b) Two parallel lines along both sides of the centreline, spaced to ensure overlap on the wreck structure: following Calder et al.'s (2007) suggestion for imaging a high-relief target.

(c) Combination of (a) and (b): following to Calder et al.'s (2007) suggestion for multiple 'beauty passes' over a high relief target. 
(d) Three long-axis parallel and three perpendicular lines: analogous to the MCA (2013) suggestion for hydrographic survey of wrecks. Note that this specifies 3-long-axis parallel lines but only "sufficient [perpendicular] lines ... so as to cover the entire length of the wreck" (MCA 2013:29). Practically, this number will depend on chosen swath width and target depth. Three lines have been chosen here for a representative demonstration of the survey design.

(e) Single line along centreline and with two oblique lines crossing at the wreck's centre point: following to the 'star' pattern suggested by Plets et al. (2013) for archaeological survey of wrecks.

(f) Four lines running oblique to the wreck and placed to form a diamond-shaped box, aligned with the wreck's long axis: not described elsewhere and tests the efficacy of oblique survey passes.

Two configurations were tested: (i) wide swath $\left(55^{\circ} / 55^{\circ}\right.$ angular sector, normal sector mode) and (ii) narrow swath ( $30^{\circ} / 30^{\circ}$ angular sector, single sector mode). All other acquisition settings remained constant (Table 1). Use of different sector modes further highlights the impact of acquisition settings given that the single sector allows a shorter pulse length and higher pulse rate.

\subsection{Data analysis}

Raw ASCII .xyz. data were imported into CloudCompare 2.8.1 (CloudCompare 2017) for visualization and analysis. No cleaning was done to ensure this was not a factor in the point cloud distribution. Individual lines were checked and corrected for misalignment and tidal-influenced offsets along the Z-axis. Subsequent analysis was separated into assessment of acquisition settings and survey design.

\subsubsection{Acquisition settings}

Point cloud density was calculated in CloudCompare ( $r=0.5 \mathrm{~m}$ and output = surface density), by calculating the number of neighbours around each point within a disc of radius of $0.5 \mathrm{~m}$. Point clouds were coloured by number of soundings per unit area and, for comparative purposes, a single colour scale encompassing the maximum and minimum values of all acquisition test lines was applied. 


\subsubsection{Survey design}

Individual lines comprising a chosen survey design (Fig. 4) were merged into a single point cloud, and surface density calculated and visualized as above. Merged point clouds were exported from CloudCompare as $0.2 \mathrm{~m}$ gridded rasters using average surface density across the $\mathrm{XY}$ and $\mathrm{YZ}$ planes, creating plan and profile views of surface density distribution. Surface density difference models were created in ESRI ArcGIS 10.3.1 and colour-coded based on the maximum and minimum values of each swath configuration to enable visual comparison.

\section{Results}

\subsection{Acquisition settings}

Surface density comparisons demonstrate the impact of different acquisition settings (Fig. 5). Varying the operating frequency has little effect on sounding density, an unsurprising result given that frequency controls beam footprint size rather than number of soundings. Although the overall wreck structure is similar at all frequencies and there is no change in density, an improvement in resolution at the higher frequencies is observed, most noticeably at the bow (including associated debris) and stern, where a small rectangular structure, possibly the base of a gantry/crane, is more clearly defined at $400 \mathrm{kHz}$ (Fig. 6).

By contrast, increasing the pulse rate has a major effect, resulting in a linear increase in density (Fig.

5). The exception is the $400 \mathrm{kHz} / 12 \mathrm{~Hz}$ pass, where only a slight density increase is observed, attributed to a temporary increase in vessel speed. In general, the density increase is not evenly distributed. Doubling or tripling the pulse rate leads to 2 to 3 times more soundings on the wreck top, but no significant increase on the sides which consistently have densities of $<25$ points $/ \mathrm{m}^{2}$.

Each decrease in overall angular sector of $20^{\circ}$ (i.e. $10^{\circ}$ each for port and starboard) decreased the swath width by 1.5 times. With each successive reduction overall surface density increased. As for pulse rate, this effect is most pronounced on the wreck top rather than its sides which still generally 
have densities $<25$ points $/ \mathrm{m}^{2}$. Steering the beams towards one side of the nadir ( $60^{\circ} / 0^{\circ}$ pass), has a detrimental effect on surface density, across both top and sides.

Changing the bottom detection mode has neglible effect on sounding density. It does however affect the absolute position of soundings and can influence the shape of the detected hull. All tested detection modes gave a similar, and sometimes identical, point distribution (Fig. 7). However, in localized areas, such as the stern (profiles A-A', E-E') and at upstanding features (profile D-D' and amidships profile $\left.A-A^{\prime}\right)$, differences of tens of centimetres up to $>1 \mathrm{~m}$ are observed. The minimum depth algorithm provides the best representation of the wreck in terms of reduced false detections.

\subsection{Survey design}

A comparison of surface density for the different survey designs is shown in Fig. 8. Using a wide swath, a single pass along the wreck centreline gives even coverage but low density $\left(<20\right.$ points $\left./ \mathrm{m}^{2}\right)$ over both the wreck top and surrounding seabed (Fig. 8 c-d). Furthermore, few beams reach the hull sides. The same is true when a narrow swath is used (Fig. 8 a-b). Despite clear increases in data density on the wreck top (c. 60-100 points $/ \mathrm{m}^{2}$ ), which allows smaller features to be partly resolved, there is only a slight improvement in imaging the hull sides.

Using two parallel lines offset from the centreline gives more even coverage of the sides relative to the top. For the wide swath, densities of up to c. 40 points $/ \mathrm{m}^{2}$ are apparent on top of the wreck, with the highest values concentrated on its port side (Fig. 8 g-h). Density on the hull is lower; generally $<30$ points $/ \mathrm{m}^{2}$, but still improved compared to the single pass. For the narrow swath, the wreck top shows an increase to c. 150 points $/ \mathrm{m}^{2}$, allowing cargo hatches and deck structures to be resolved. Hull-side detections remain low; <c. 50 points $/ \mathrm{m}^{2}$ (Fig. 8 e-f). This also shows that line placement is critical for effective survey of an upstanding wreck. The wider swaths were set $25 \mathrm{~m}$ from the centreline, and while they provided good coverage of the vertical sides (data density comparable to the surrounding seabed), overlap was insufficient to give good coverage of the wreck 
top. Conversely, the narrow swaths were $10 \mathrm{~m}$ from the centreline, allowing overlap and high data density on the wreck top. These lines also gave reasonable coverage of the sides, but at reduced density compared to the surrounding seabed.

Combining the central and offset lines gives coverage of both the hull sides and wreck top. Unsurprisingly, the highest density is from the wreck top where overlap is greatest. For the narrow swath, density of c. 200 points $/ \mathrm{m}^{2}$ is the norm, allowing good definition of cargo hatches and superstructure elements (Fig. $8 \mathrm{i}-\mathrm{j}$ ). Improvements were also noted on the wide swath, with density of c. 40-60 points $/ \mathrm{m}^{2}$ achieved albeit concentrated on the port side of the deck due to greater overlap between the central and port offset line (Fig. 8 k-I). Again, this highlights the critical placement of offset lines to ensure even coverage. Conversely, for both swath widths, since imaging of the hull sides was only achieved by the offset lines, adding the central line gives no improvement on use of offset lines alone.

The MCA-style combines the centreline-aligned passes with three perpendicular passes. Improvements are concentrated on the wreck top with no visible improvement on the sides. Again, improved density results from overlapping of multiple passes. This design also highlights the role of the angular sector and resulting swath width. Coverage is particularly poor for the narrow swath because the small ensonified area means that three perpendicular lines are insufficient to cover the wreck (Fig. 8 m-n). Only the central section and part of the detached bow were ensonified and show increased density. In the central area, the increase of up to $300-400$ points $/ \mathrm{m}^{2}$ allowed very clear definition of the superstructure. In contrast, the wider swath more efficiently covered the wreck but at the cost of reduced surface density, reaching only up to c. 60-90-points $/ \mathrm{m}^{2}$ in limited areas where the swaths overlap (Fig. 8 o-p).

For both swath widths, the star-shaped pattern allowed the entire wreck to be ensonified. For the wide swath, coverage on the wreck top was even (particularly compared to the centreline-aligned passes) and reached densities of c. 40-60 points $/ \mathrm{m}^{2}$ (Fig. $8 \mathrm{~s}$-t). For the narrow swath, greater 
densities were achieved - up to 300 points $/ \mathrm{m}^{2}$ - but concentrated in the wreck centre where all three passes overlapped (Fig. 8 q-r). For both swath widths, coverage was better on the wreck top compared to its sides, where only sparse soundings were returned ( $<20$ points $/ \mathrm{m}^{2}$ for wide swath; $<50$ points $/ \mathrm{m}^{2}$ for narrow swath).

The limited coverage of the narrow swath is further highlighted by the diamond-shaped box design. While locally high data densities were achieved (up to 200 points $/ \mathrm{m}^{2}$ ) where passes overlapped, the wreck was missed apart from its bow and stern (Fig. $8 \mathrm{u}$-v). Conversely, the wide swath allowed the wreck to be almost entirely ensonified under this survey design. Localized increases in density of c. 30-40 points $/ \mathrm{m}^{2}$ are apparent on the wreck top as well as densities ranging from c. $15-30$ points $/ \mathrm{m}^{2}$ on the hull sides (Fig. 8 w-x). However, general coverage on both the top and sides is uneven compared to use of centreline-aligned passes.

In terms of the efficacy of previous published strategies, based on comparison of difference models of surface density the controlled experiment found the following (Fig. 9):

MCA-suggested style (MCA 2013) versus central three lines (Calder et al. 2007 analogue)

Using the wide swath, the MCA-style results in a minor improvement on the central three lines, focused primarily on the bow and stern where overlap with perpendicular lines is greatest. Little significant difference is observed on the sides, with the exception of the inside of the detached bow which is orientated at right angles to the rest of the wreck. With the narrow swath, the MCA-style gives higher sounding density only in the wreck centre where the perpendicular line overlaps the centreline-aligned lines. No significant improvement along the sides is observed, even where the central perpendicular line overlaps.

MCA-suggested style (MCA 2013) versus star-shape (Plets et al. 2013)

Using the wide swath, the MCA-style generally provides higher density over the wreck and seabed, except for patches on the starboard side of the deck, which show a minor improvement using the 
star-shape. This results from enhanced overlap of the oblique lines. For the hull sides, the MCA-style is clearly better because the offset long-axis parallel lines give consistent imaging. With the narrow swath, the MCA-style outperforms the star-shape over the wreck top. While the star-shape has a triple overlap, use of a narrow swath means this occurs only over the wreck centre. Conversely, the close offsets of the centreline-parallel lines provide overlap along the entire deck, enhanced in the centre by the central perpendicular line. Improvement on the sides is minor except for the detached bow section.

Central three lines (Calder et al. 2007 analogue) versus star-shape (Plets et al. 2013)

Using the wide swath, little difference is noted between both strategies. However, the 3 central lines give reduced density on the wreck top as the star-shape gives more concentrated overlap. Conversely, the sides show consistent improvement when imaged by the offset long-axis parallel lines. With the narrow swath, the three central lines result in large areas of little change or decreased density around the wreck. However, on the wreck top, this reduction is less apparent, and concentrates only in a few small areas. The central three lines are naturally better at the bow and stern where the star-shape does not overlap. Differences between the survey strategies along the sides are marginal, barring the detached bow (better imaged by the central three lines) and a patch of sediment piled up against the hull (better imaged by the star-shape).

\section{Discussion}

If the choice of MBES and survey vessel are removed from the equation, and good hydrographic practice (e.g. MBES calibration, sound velocity corrections, accurate dimensional survey) is followed (IHO 2008; 2011; Plets et al. 2013; USACE 2013), there are two key considerations in acquiring HD data over a historic wreck: i) acquisition settings and ii) survey design.

\subsection{Acquisition settings}


Operating frequency is often equated with image quality as a result of the positive relationship between frequency and resolution. Consequently many sidescan and MBES systems are marketed on this basis (Quinn et al. 2005). However, it is important to consider that frequency does not directly control resolution (see equations 1 and 2), but does so indirectly via its relationship with pulse length and beam aperture. Smaller apertures and shorter pulses lengths give smaller footprints, and they are enabled at higher frequencies. More important is to consider the ability of a given MBES system to provide short pulse lengths and small apertures, as these can differ between different systems, even at the same frequency. That said, for a given system, higher frequency should produce a smaller footprint. For example, for the Kongsberg EM2040, at 30 m water depth, each beam will ensonify a minimum of $50 \mathrm{~cm}^{2}$ (at the nadir) using the $200 \mathrm{kHz}$ frequency, reducing to a minimum of $11 \mathrm{~cm}^{2}$ using the $400 \mathrm{kHz}$ frequency. Depending on the bottom tracking algorithm used, a depth value will be extracted from this footprint - either an average or a minimum depth value. The smaller the footprint, the more representative the extracted value and the sharper the resulting imagery (Fig. 6). Aside from footprint size, the main function of frequency is to allow the MBES to be effective at deeper depths. Therefore, if there is a choice in system or a multi-frequency MBES is available, then the highest possible frequency suitable for the water depth in question should be chosen. This alone though will not guarantee HD imagery.

As demonstrated above, sounding density and distribution is also important for HD imaging and is not affected by operating frequency (Fig. 5). More important is to combine small footprints with high sounding density (ideally centimetric spacing). Previous work has identified that slow survey speed does this very effectively (Bates et al. 2011). However, speeds $<4 \mathrm{kn}$ can be hard to achieve on many vessels without losing the ability to maintain a constant heading. This also risks introducing data artefacts by increasing the amount of motion compensation. Moreover, speed reduction only affects data density in the along-track direction. If slow speed is unachievable, a similar effect can be obtained by increasing the pulse rate (Fig. 5). The disadvantage is that high rates are only feasible in 
shallow water. Increased data density in the across-track direction can be achieved by using a smaller angular sector to confine soundings within a narrower swath (Fig. 5).

Bottom detection algorithms have little effect on data density, and Fig. 7 validates the standard recommendation (based on safety of navigation) of minimum depth mode. A more important consideration is that different algorithms can give different absolute positions for the same target (Fig. 7). Therefore, if conducting repeat surveys, it is essential that the same detection algorithm is used throughout. Similarly, given the demonstrable variation in the acquired data resulting from use of different pulse rates, frequencies and angular sectors, it is essential that all acquisition settings are kept constant between repeat surveys to ensure that data from different timesteps are directly comparable and that detected changes are not artefacts introduced by discrepancies in imaging. To support resurvey, metadata on acquisition settings should be recorded, and following best practice, archived along with the acquired survey data in a recognized Data Archive Centre such as the UK's Marine Environmental Data and Information Network (MEDIN) or a local equivalent.

\subsection{Survey design}

The controlled experiment demonstrates that increasing sounding density on the horizontal deck is easily accomplished by decreasing the angular sector and running multiple overlapping passes. However, each approach has drawbacks. For the narrow swath, large increases in data density are achieved but at the cost of uneven coverage since gaps are present between survey passes. This is most noticeable for the diamond and star-shaped designs: the former missed the wreck while the latter had greatly increased data density only over the amidships part of the deck. On the other hand, overlapping passes at any swath width or direction is effective at increasing data density and mitigating an inability to survey at slow speed. This is most obvious for the wide swath, since it is broad enough to cover most of the wreck in a single pass. However, increasing the number of passes makes it essential that a high precision positioning system (DGPS or RTK) is used, allowing individual 
lines to be merged into a single accurate model without 'blurring' caused by positional discrepancies between survey passes (Bates et al. 2011; Calder et al. 2007).

Ensuring an even distribution of soundings is harder since shipwrecks consist of vertical, horizontal and angled surfaces orientated in different directions, thus creating acoustic shadows which vary depending on the direction of ensonification. The largest shadows are on the vertical hull sides and often result in a pattern of good density on the horizontal deck versus little to no coverage of the sides (Fig. 1). The controlled experiment shows that passes run directly over the wreck, regardless of direction, cannot remedy this. Thus, the star and diamond designs only have a localized effect (e.g. the broken-off bow section), while perpendicular lines have little, if any, effect. The most consistently effective way of increasing hull side detections requires lines aligned with, but offset from, the wreck centreline (Fig. 8 e-l; Calder et al. 2007). The key consideration here is the offset distance relative to swath width: if the lines are too close to the centreline, the hull sides remain in the acoustic shadow of the deck, particularly if overhangs are present. Conversely, if the swath width is too narrow and the lines are too far offset, the outer beams will either not reach the hull, or reach only part-way up it. The appropriate balance therefore depends on the a) dimensions of the wreck and b) angular sector used. While imaging of the full hull structure may not be the primary interest for navigational/hydrographic purposes, it is crucial for heritage management, as this needs to consider the integrity of the entire wreck, its preservation state and likelihood of collapse.

\subsection{Optimised survey strategy}

Lessons learnt from the controlled experiment allow recommendations for optimizing acquisition settings and survey design to achieve HD imaging. These can be used for planning bespoke surveys targeted at specific wrecks, or to facilitate embedding of HD imaging within surveys conducted for other purposes. Application of the optimized strategy is demonstrated in Fig. 10. In this example, data acquired using the same MBES and survey platform but different acquisition settings and survey strategies resulted in standard density (Fig. $10 \mathrm{~A}$ and C) and HD (Fig. $10 \mathrm{~B}$ and D) point clouds. 
The HD point cloud was based on 9 passes ( 5 centreline-parallel, 2 oblique [star-shape] at $30^{\circ} / 30^{\circ}$ [single sector] plus 2 wider centreline-parallel offsets at $55^{\circ} / 55^{\circ}$ [normal sector]). The standard density point cloud was generated by 3 survey passes running NNW-SSE obliquely across the wreck using $55^{\circ} / 55^{\circ}$ (normal sector), analogous to a broad-scale seabed mapping program (e.g. Fig. 3b). The standard density approach succeeded in imaging the entire wreck and giving some impression of its characteristics; e.g. the forward cargo hatch and amidships structure. However, details are fuzzy and there are large acoustic shadows on the port side of the wreck. By contrast, the HD imagery shows the entire wreck, with minimal shadows and in much greater detail. Both forward and aft cargo hatches are clear, the central structure and associated elements are also better resolved.

\subsubsection{Acquisition settings}

Surveys should use the highest frequency and pulse rates appropriate for water depth. Survey speed should be reduced to a reasonable minimum - ideally to $<4 \mathrm{kn}$ - which still allows the survey vessel to maintain a constant heading. The swath should cover c. 2-4 times the wreck width (WW). As the area ensonified depends on the water depth (WD), the requisite angular sector (AS) is also depthdependent. Equation 4 can be used to determine the appropriate AS:

$$
A S=2 \times \tan ^{-1}\left(\frac{W W}{W D}\right)
$$

For example, a $15 \mathrm{~m}$ wide wreck in $30 \mathrm{~m}$ water depth requires a total angular sector of $53^{\circ}\left(27^{\circ} / 27^{\circ}\right)$. If surveying an unknown wreck, a reconnaissance line at the widest angular sector possible should be run initially to determine its dimensions. Once established, subsequent swath widths can be derived using Equation 4.

\subsubsection{Survey design}

Survey lines should be run parallel to the wreck's long-axis (see also Calder et al., 2007) and comprise at least one line along the centreline and two offset parallels spaced to achieve $100 \%$ overlap with the central swath. All lines should be run at the angular sector specified in Equation 4. 
This should facilitate good data density over most of the wreck top and sides and compensate for acoustic shadows created by complex surfaces (Fig. $8 \mathrm{i}-\mathrm{I})$ ).

Depending on water depth and overhang angles, offset lines may image the hull sides. To be certain, at least two additional offset parallels are recommended, spaced further out from the centreline. These can be run at a wider angular sector, to image the sides from a shallower angle thus mitigating overhangs. This is demonstrated in Fig. 8 (compare g-h, k-I with e-f, i-j), which shows that wider swaths spaced further out achieve densities similar to narrow swaths closer to the wreck (see also Kongsberg 2013). Precise values for spacing and swath width cannot be specified since these depend on wreck height, depth and angle of the hull sides. They can be decided upon review of the results of the central lines specified above. If wider swaths and larger spacings are used, the option (if available) to set beam spacing as equidistant should be selected. This ensures that beams are not concentrated in the nadir, so more of them point towards the outer swath where the target is located.

Perpendicular and oblique lines effectively increase sounding density through enhanced overlap and provide different angles of ensonification which can eliminate acoustic shadows on parallel lines. If used, enough lines spaced to ensure $100 \%$ overlap and covering the entire wreck length should be used to avoid gaps (see also MCA 2013). Note that if this this recommendation is followed, the optimized design largely follows that specified by the MCA (2013) for hydrographic survey but with additional lines. This implies that data density and coverage will be sufficient to calculate minimum safe clearance, and if additional hydrographic specifications are followed (e.g. recording water column data: MCA 2013), then the strategy becomes valid for both HD historic wreck imaging and hydrographic survey. Alternatively, if data from the central three lines can be reviewed immediately after acquisition, perpendicular and oblique lines can be used in a targeted manner, to collect additional data on features of interest or eliminate acoustic shadows. 
Repeat (time-lapse) surveys must use identical acquisition settings and survey strategies to ensure that point clouds are directly comparable, since it is clear that sounding density, distribution and resolution vary with acquisition settings and survey strategy.

These recommendations represent the minimum requirements for collecting HD imagery. If time and cost permits, additional lines should be collected since redundant lines can always be removed from the final 3D model. By example, the very high-density point cloud for SS Chirripo (Fig. 11) comprises data from eleven passes at $55^{\circ} / 55^{\circ}$ angular sector, seven passes at $30^{\circ} / 30^{\circ}$ and includes long axis-parallel, long axis-perpendicular and oblique lines. Where multiple passes are used, highprecision DGPS/RTK and MRU and optimal control of environmental and sound velocity conditions are essential to allow data from individual passes to be successfully merged.

A final consideration relates to water depth. The optimized strategy outlined above has been successfully used on wrecks down to $70 \mathrm{~m}$. However, with any hull-mounted system, given the control that range exerts on resolution and density, the need for lower frequencies at greater depth, and the inability to use high pulse rates (equations 1 to 3 ), image quality naturally diminishes as target depth increases. The only options here, short of ROV or pole-mounting the transceiver, are multiple passes and narrow angular sectors to maintain sounding density. Even so, acquired point clouds will still likely be of lower definition than in shallow water.

\section{Conclusion}

HD imaging of shipwrecks is important for research into, and management of, the marine historic environment. At present, the most widely used technique is MBES. However, image quality can vary considerably depending on the MBES hardware and survey strategy. Although there is some guidance on shipwreck survey (e.g. Bates et al. 2007; Calder et al. 2007; MCA 2013; Plets et al. 2013), little has been published on precisely which acquisition settings and survey design most effectively 
enable HD imagery. Other existing recommendations, most notably the 'low and slow' approach (Bates et al. 2011) are valid, but not always achievable with hull-mounted MBES setups.

The controlled experiment presented here has objectively tested acquisition settings and survey design using a conventional hull-mounted MBES and, from this, developed an optimized strategy for HD data acquisition. The core observation was that different acquisition settings and survey strategies result in variable sounding resolution, density and distribution. Pulse rate and angular sector exert a strong control on density, supplementing the previously identified role of survey speed and MBES-target distance (Bates et al. 2007; 2011). Operating frequency, often seen as directly linked to image quality, affects beam footprint size and thus resolution rather than data density. The derived recommendations focus on combining a high pulse rate with high frequency, narrow angular sector and slow speed, to achieve a dense accurate point cloud. One setting tested detection algorithm - had no impact on data density or resolution, but resulted in variations in the position of individual soundings. This highlights the need to maintain identical settings between repeat surveys conducted for time-lapse analysis.

With regard to survey strategy, the controlled experiment found that existing proposed strategies (Calder et al. 2007; MCA 2013; Plets et al. 2013) are valid but varied in effectiveness. The most efficient are multiple lines oriented parallel to the wreck centreline (Calder et al. 2007; MCA 2013). Additional perpendicular (MCA 2013) or oblique passes (Plets et al. 2013) can then be added depending on the wreck configuration, features of interest, time available for survey or to increase data density. Additional observations, not clear from either MCA (2013) or Plets et al. (2013) concerned suggested line spacing and the role of offset lines in imaging the vertical hull sides. The adoption of this optimized approach would result in high-definition 3D imaging of historic wrecks to benefit archaeological research, promote underwater cultural heritage, inform policy makers and develop effective mitigation strategies to minimise loss of the fragile underwater resource.

\section{Acknowledgements}


This work was supported by the Marine Institute of Ireland's ship-time programme (APP-CV15009: World War I shipwrecks in the Irish Sea: commemoration, visualization and heritage management). We thank the crew of the Celtic Voyager; without your patience and enthusiasm, we could not have achieved this. Thanks to Bob Kinnear (Maritime and Coastguard Agency) for provision of SS Neotsfield data and Karl Brady (Dept. of Culture, Heritage and the Gaeltacht) for supporting work in Republic of Ireland waters. Finally, we are indebted to the late Martin Dean. His support and guidance were essential in bringing this project to fruition. 


\section{References}

Adams J. (2001) Ships and boats as archaeological source material. World Archaeology 32:292-310

Astley A, Dix JK, Thompson C, Sturt F (2014) A seventeen year, near-annual, bathymetric time-series of a marine structure (SS Richard Montgomery). In: Cheng L, Draper S \& An H (Eds.) Scour and Erosion:

Proceedings of the 7th International Conference on Scour and Erosion.Taylor \& Francis, London, pp 715724

Ballard R, Archbold R (1987) The Discovery of the Titanic. Hodder \& Stoughton, London

Bates CR, Dean M, Lawrence M, Robertson P, Tempera F, Laird S (2007) Innovative approaches to Rapid Archaeological Site Surveying and Evaluation (RASSE). Report prepared for English Heritage. University of St. Andrews, St Andrews

Bates CR, Dean M, Lawrence M, Robertson P (2011) Geophysical methods for wreck-site monitoring: the Rapid Archaeological Site Surveying and Evaluation (RASSE) programme. International Journal of Nautical Archaeology 40: 404-416

Bellec V, Bøe R, Rise L, Lepland A, Thorsnes T, Bjarnadóttir L (2017) Seabed sediments (grain size) of Nordland VI, offshore north Norway. Journal of Maps 13:608-620

Brady K, McKeown C, Lyttleton J, Lawler I (2012) Warships, U-Boats \& Liners. A guide to shipwrecks in Irish waters. The Stationary Office, Dublin

Calder B, Forbes D, Mallace D (2007) Marine Heritage Monitoring with High-Resolution Survey Tools: Scapa Flow 2001-2006. Proceedings of U.S. Hydro Conference May 2007

Calvert J, Strong J, Service M, McGonigle C, Quinn R (2015) An evaluation of supervised and unsupervised classification techniques for marine benthic habitat mapping using multibeam echosounder data. ICES Journal of Marine Science 72:1498-1513

CloudCompare (version 2.8.1) [GPL software] (2017) Retrieved from http://www.cloudcompare.org 
Dean M, Lawrence M, Rowland C (2007) Visualizing high-resolution multibeam shipwreck data.

Proceedings of U.S. Hydro Conference May 2007

Eriksson N, Rönnby J (2012) 'The ghost ship'. An intact Fluyt from c. 1650 in the middle of the Baltic Sea. International Journal of Nautical Archaeology 41:350-361

Fernandez-Montblanc T, Quinn R, Izquierdo A, Bethencourt M (2016) Evolution of a shallow water wavedominated shipwreck site: Fougueux (1805), Gulf of Cadiz. Geoarchaeology 31:487-505

Flatman J (2003) Cultural biographies, cognitive landscapes and dirty old bits of boat: 'theory' in maritime archaeology. International Journal of Nautical Archaeology 32:143-157

Gibbins D, Adams J (2001) Shipwrecks and maritime archaeology. World Archaeology 32:279-291

Hughes Clarke JE, Lamplugh M, Czotter K (2006) Multibeam water column imaging: improved wreck leastdepth determination. Proceedings of the Canadian Hydrographic Conference May 2006

Hughes Clarke JE (2017) Multibeam echosounders. In: Micallef A, Krastel S, Savini A (eds.) Submarine Geomorphology. Springer, pp 25-42

IHO (2008) IHO Standards for Hydrographic Surveys - Standards and Specifications Publication S-44 (5 $5^{\text {th }}$ Edn). International Hydrographic Bureau. https://www.iho.int/iho_pubs/standard/S-44_5E.pdf (accessed April 2018)

IHO (2011) Manual on Hydrography - Capacity Building Publication C-13 (1 $1^{\text {st }}$ Edn). International Hydrographic Bureau. https://www.iho.int/iho_pubs/CB/C13_Index.htm (accessed April 2018) Kongsberg (2013). EM Technical Note. Detector modes is SIS for EM2040, EM2040C and EM3002. https://www.km.kongsberg.com/ks/web/nokbg0397.nsf/AllWeb/45B1BC0CF3EE4D06C1257C7E002DA3F A/\$̧file/Kongsberg-EM-Technical-Note-EM-Detector-Modes-in-SIS.pdf?OpenElement (accessed August 2017) 
Kongsberg (2016). EM2040 Multibeam Echosounder Specifications.

https://www.km.kongsberg.com/ks/web/nokbg0240.nsf/AllWeb/C75143F8AA145B48C12575E500276CA

4?OpenDocument (accessed August 2017)

Lecours V, Dolan M, Micaleff A, Lucieer V (2016). A review of marine geomorphometry, the quantitative study of the seafloor. Hydrology and Earth System Sciences 20:3207-3244

Lurton X (2010). An Introduction to Underwater Acoustics. Principles and Applications. Springer, Heidelberg

Maarleveld T, Guérin U, Egger B (2013) Manual for Activities directed at Underwater Cultural Heritage.

Guidelines to the Annex of the UNESCO 2001 Convention. UNESCO

Manders M (2009) Multibeam recording as a way to monitor shipwreck sites. In: MACHU Final Report NR.

3 - Managing Cultural Heritage Underwater. pp 59-66

Mayer L (2006) Frontiers in seafloor mapping and visualization. Marine Geophysical Researches 27:7-17

MCA (2013) UK Civil Hydrography Programme. Survey Specification.

http://www.channelcoast.org/ccoresources/specificationsandbriefs/ (accessed August 2017)

McCartney I (2016) Jutland 1916: the Archaeology of a Naval Battlefield. Bloomsbury, London

Mertes J, Zant C, Gulley J, Thomsen T (2017) Rapid, quantitative assessment of submerged cultural resource degradation using repeat video surveys and Structure from Motion. Journal of Maritime Archaeology 12:109-107

$\varnothing$ degård $\varnothing$, Hansen R, Singh H, Maarleveld T (2018).Archaeological use of Synthetic Aperture Sonar on deepwater wreck sites in Skagerrak. Journal of Archaeological Science 89:1-13 
Plets R, Quinn R, Forsythe W, Westley K, Bell T, Benetti S, McGrath F, Robinson R (2011) Using multibeam echo-sounder data to identify shipwreck sites: archaeological assessment of the Joint Irish Bathymetric Survey data. International Journal of Nautical Archaeology 40:87-98

Plets R, Clements A, Quinn R, Strong J (2012) Marine substratum map of the Causeway Coast, Northern Ireland. Journal of Maps 8:1-13

Plets R, Dix J, Bates CR (2013) Marine Geophysics Data Acquisition, Processing and Interpretation. Guidance notes. English Heritage, London

Quinn R, Dean M, Lawrence M, Liscoe S, Boland D (2005) Backscatter responses and resolution considerations in archaeological side-scan sonar surveys: a control experiment. Journal of Archaeological Science 32:1252-1264

Quinn R, Boland D (2010) The role of time-lapse bathymetric surveys in assessing morphological change at shipwreck sites. Journal of Archaeological Science 37:2938-2946

Sacchetti F, Benetti S, Georgiopoulou A, Dunlop P, Quinn R (2012) Geomorphology of the Irish Rockall Trough, North Atlantic Ocean, mapped from multibeam bathymetric and backscatter data. Journal of Maps 7:60-81

Strong J, Service M, Plets R, Clements A, Quinn R (2012) Marine substratum and biotope maps of the Maidens/Klondyke bedrock outcrops, Northern Ireland. Journal of Maps 8:129-135

UNESCO (2001) Convention on the Protection of the Underwater Cultural Heritage. http://www.unesco.org/new/en/culture/themes/underwater-cultural-heritage/2001-convention/officialtext/. (accessed August 2017)

USACE (2013) Hydrographic Surveying Engineer Manual (EM 1110-2-1003). US Army Corp of Engineers. http://www.publications.usace.army.mil/USACE-Publications/EngineerManuals/?udt_43544_param_page=4 (accessed April 2018) 
Tables

Table 1 Acquisition settings tested over SS Polwell

\begin{tabular}{|c|c|c|}
\hline Parameter & Acquisition settings test & Survey design test \\
\hline Frequency & $\begin{array}{l}\text { Varied: } 200 \text { kHz, } 300 \text { kHz, } 400 \\
\text { kHz }\end{array}$ & Constant: 400 kHz \\
\hline Pulse rate & Varied: $4 \mathrm{~Hz}, 8 \mathrm{~Hz}, 12 \mathrm{~Hz}$ & Constant: maximum (up to $50 \mathrm{~Hz}$ ) \\
\hline $\begin{array}{l}\text { Angular sector (overall } \\
\text { and port/starboard) }\end{array}$ & $\begin{array}{l}\text { Varied: } 40^{\circ}\left(20^{\circ} / 20^{\circ}\right), 60^{\circ} \\
\left(30^{\circ} / 30^{\circ}\right) \text { and }\left(0^{\circ} / 60^{\circ}\right), 80^{\circ} \\
\left(40^{\circ}, 40^{\circ}\right)\end{array}$ & Varied: $110^{\circ}\left(55^{\circ} / 55^{\circ}\right), 60^{\circ}\left(30^{\circ} / 30^{\circ}\right)$ \\
\hline Sector mode & $\begin{array}{l}\text { Constant: Normal (three } \\
\text { sectors) }\end{array}$ & $\begin{array}{l}\text { Varied: Normal (three sectors), } \\
\text { single sector (only middle sector) }\end{array}$ \\
\hline Beam spacing & $\begin{array}{l}\text { Constant: High Density } \\
\text { Equidistant }\end{array}$ & Constant: High Density Equidistant \\
\hline $\begin{array}{l}\text { Pulse length (lower } \\
\text { values for single sector, } \\
\text { higher for normal sector } \\
\text { at a given frequency) }\end{array}$ & $\begin{array}{l}\text { Constant: Short CW (200 } \\
\text { kHz=70 } \mu \mathrm{s} ; 300 \mathrm{kHz}=70 \mu \mathrm{s} ; 400 \\
\mathrm{kHz}=50 \mu \mathrm{s})\end{array}$ & $\begin{array}{l}\text { Constant: Short CW }(200 \mathrm{kHz}=35-70 \\
\mu \mathrm{s} ; 300 \mathrm{kHz}=35-70 \mu \mathrm{s} ; 400 \mathrm{kHz}=25- \\
50 \mu \mathrm{s})\end{array}$ \\
\hline Bottom detection & $\begin{array}{l}\text { Varied: Normal, minimum } \\
\text { depth and tracking }\end{array}$ & Constant: minimum depth \\
\hline
\end{tabular}




\section{Figures}
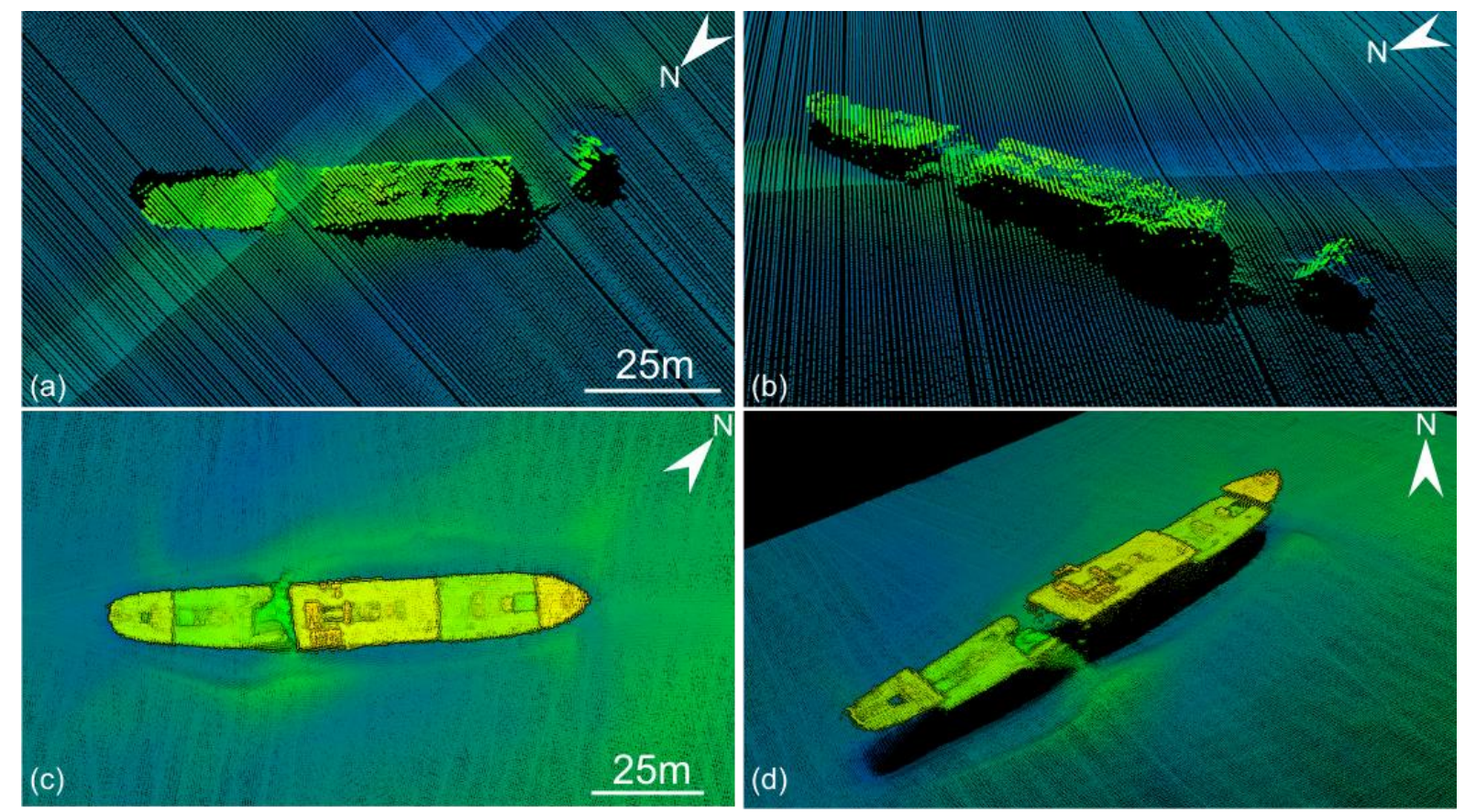

(c)
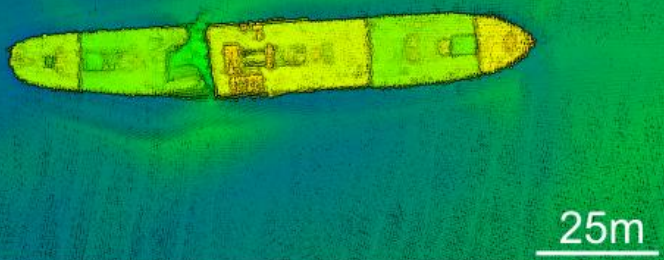

(d)

Fig. 1 MBES data showing variable quality of imaging over two historic wrecks, both torpedoed 1918 in the western Irish Sea. SS Polwell; acquired as part of regional hydrographic survey by the INFOMAR programme, no wreck-specific imaging guidelines used: (a) Top view showing deck, and (b) oblique view showing the lack of data points returning from the hull sides. SS Neotsfield acquired using UK Maritime and Coastguard Agency (MCA) guidelines for hydrographic wreck survey (MCA, 2013). (a) Top view showing considerable detail of deck structure, and (d) oblique view showing the lack of data points returning from the hull sides. Difference in detail between the two wrecks relates to both survey strategy and MBES system used (Neotsfield: Kongsberg EM2040; Polwell: Kongsberg EM3002). 


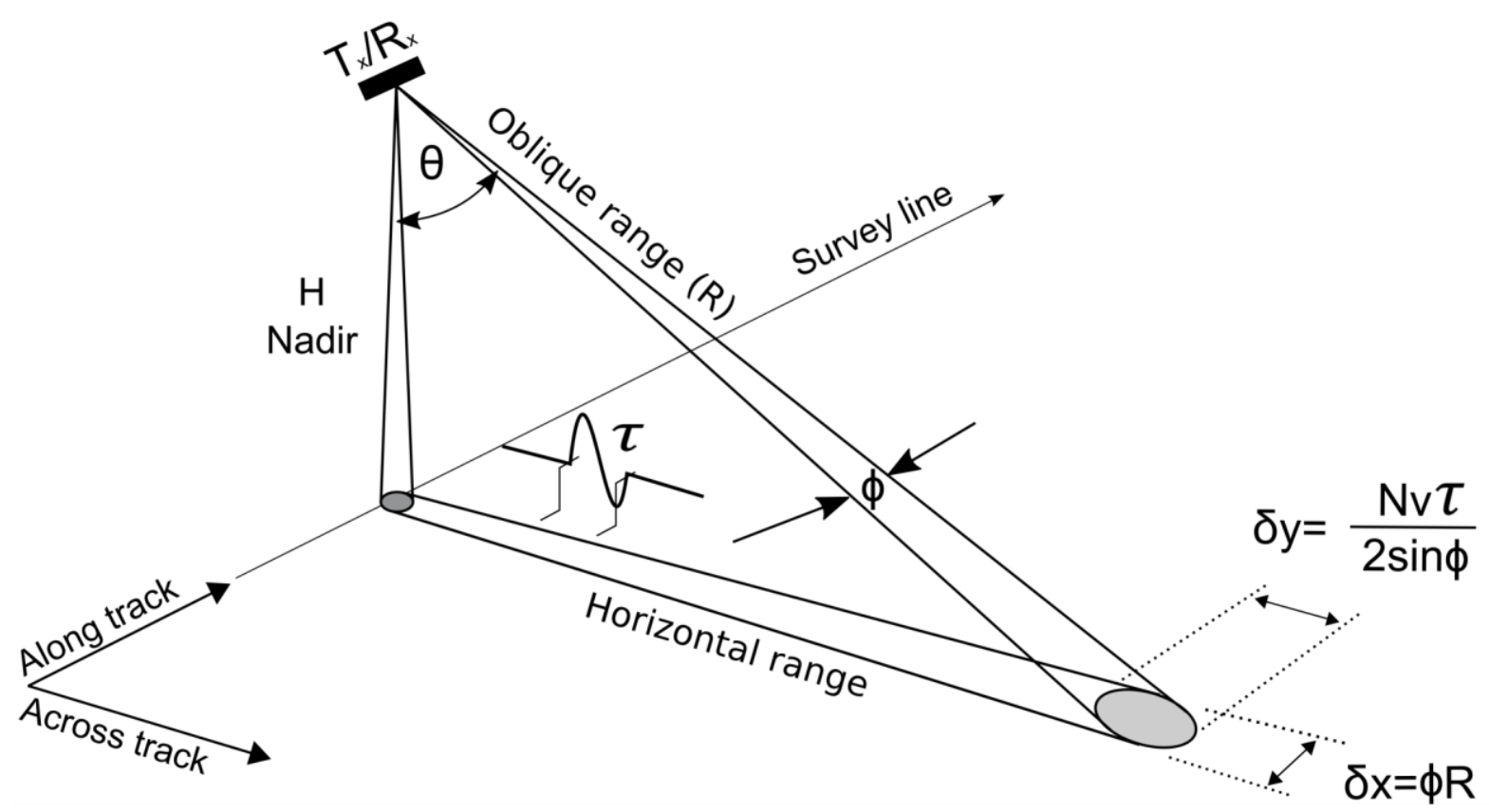

Fig. 2 Multibeam echosounder geometry

30 


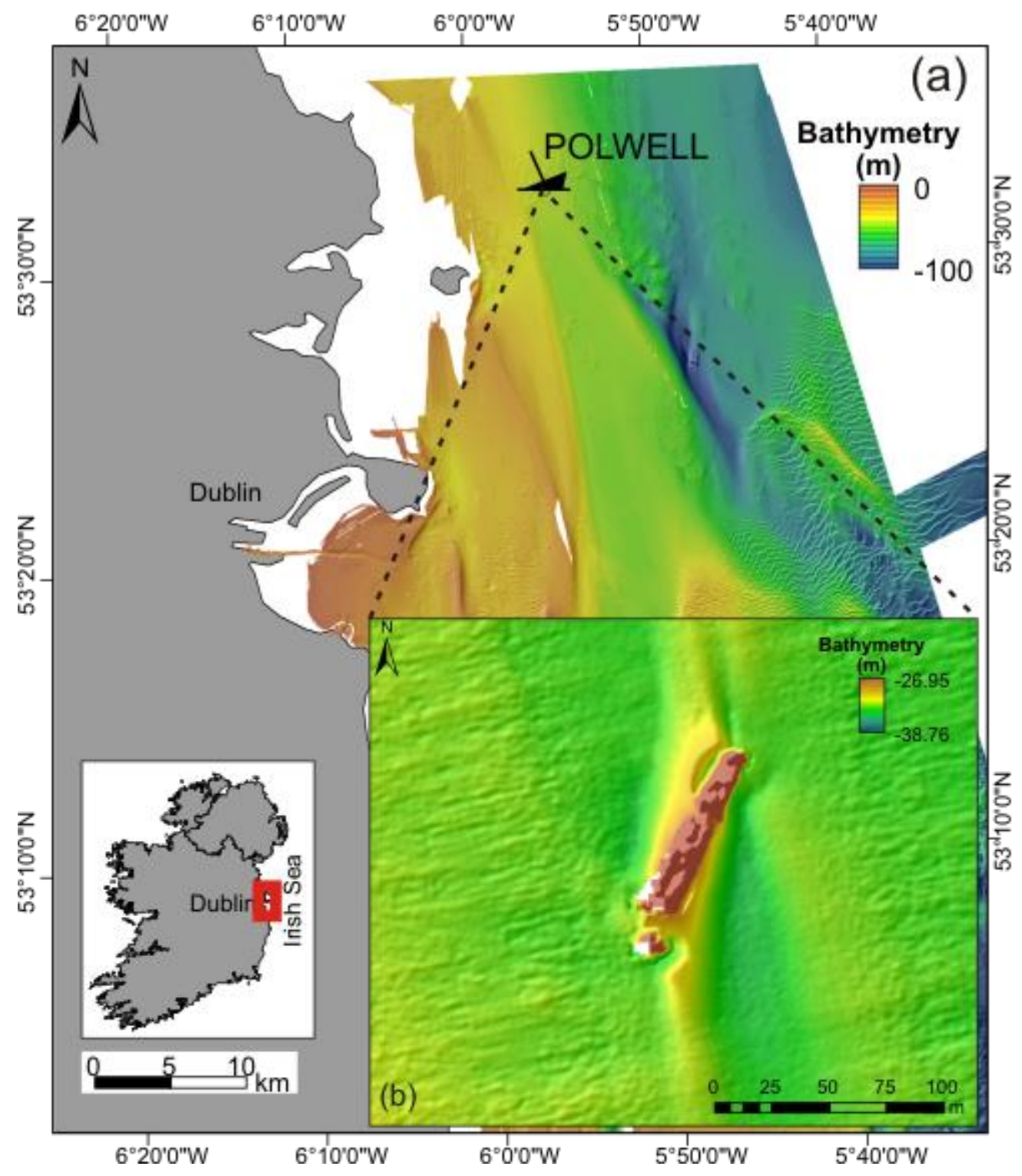

Fig. 3 (a) Location of SS Polwell in the western Irish Sea, off Dublin (Republic of Ireland); (b) MBES image of SS Polwell acquired using standard hydrographic survey parameters and displayed as a $1 \mathrm{~m}$ gridded elevation model (all bathymetry data collected by the INFOMAR programme) 

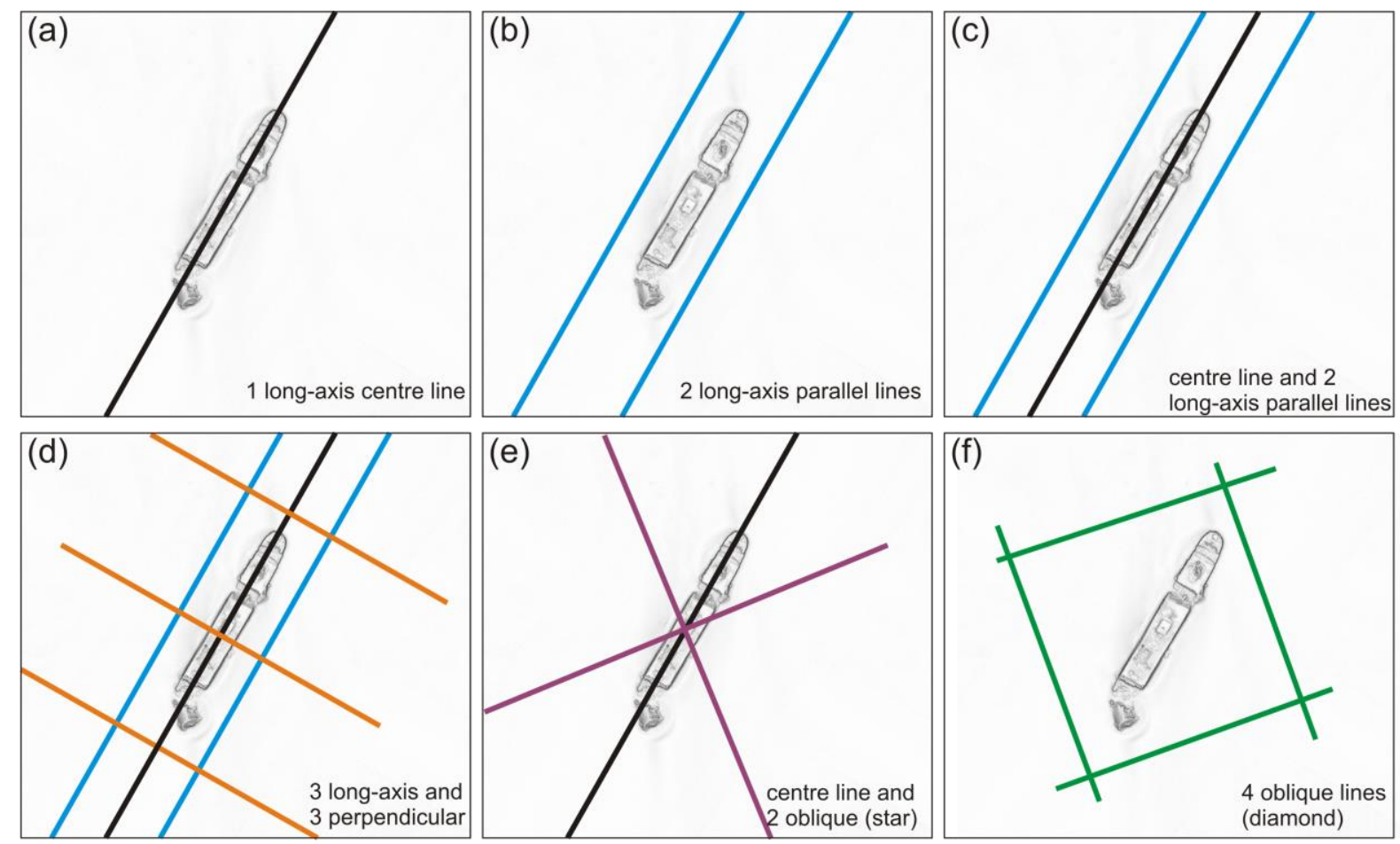

Fig 4 Survey designs tested over SS Polwell 


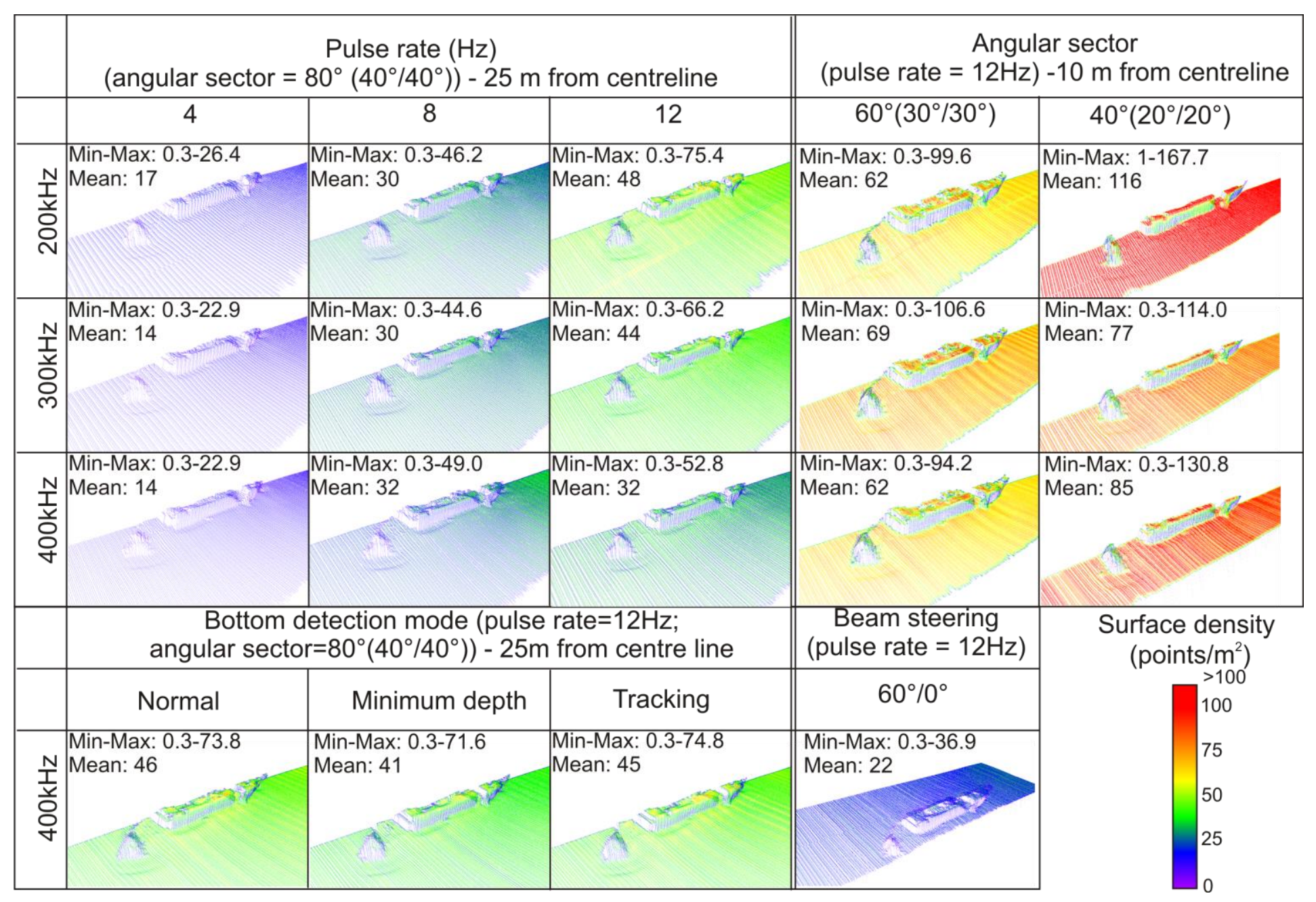

Fig. 5 Matrix of change in sounding surface density according to the changes in acquisition settings 


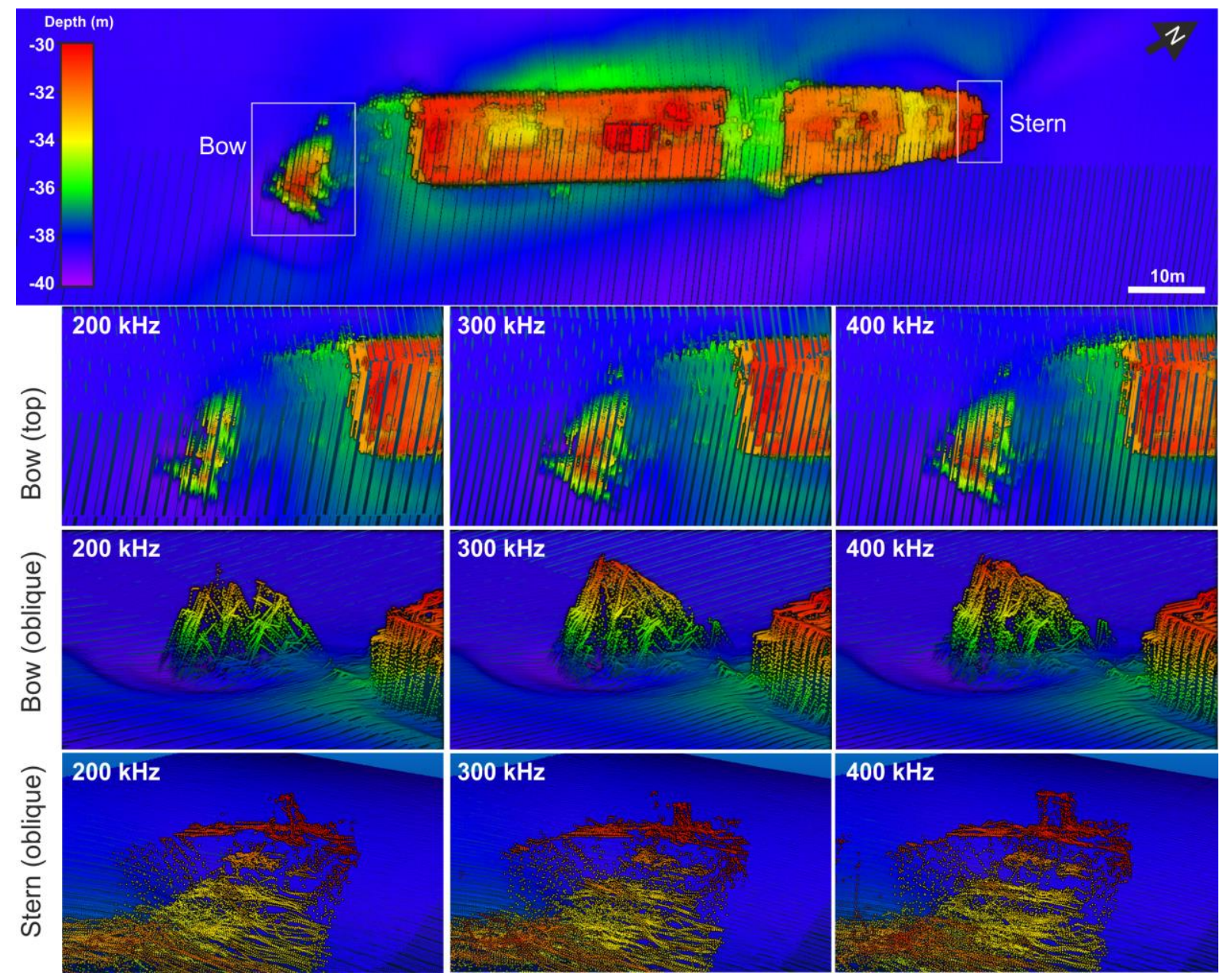

Fig. 6. Point clouds showing bow and stern of SS Polwell imaged at different operating frequencies.

Note the improvement in definition at higher frequencies particularly of the top of the bow and a rectangular feature at the stern. White boxes on the overall wreck image show the location of zoomed views presented underneath 


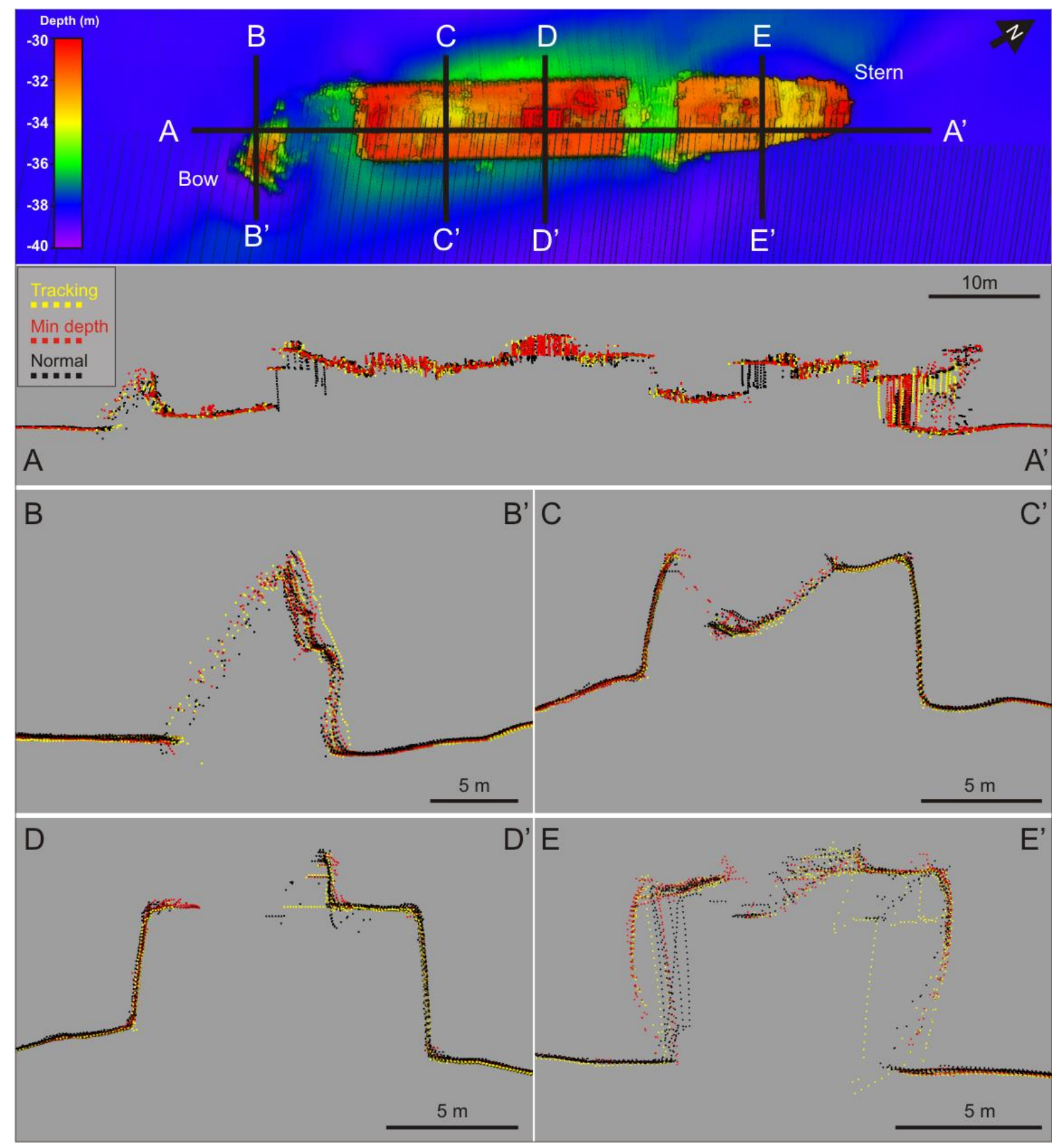

Fig. 7 Profiles along and across SS Polwell from survey passes with different bottom detection modes (normal, min depth, tracking) 


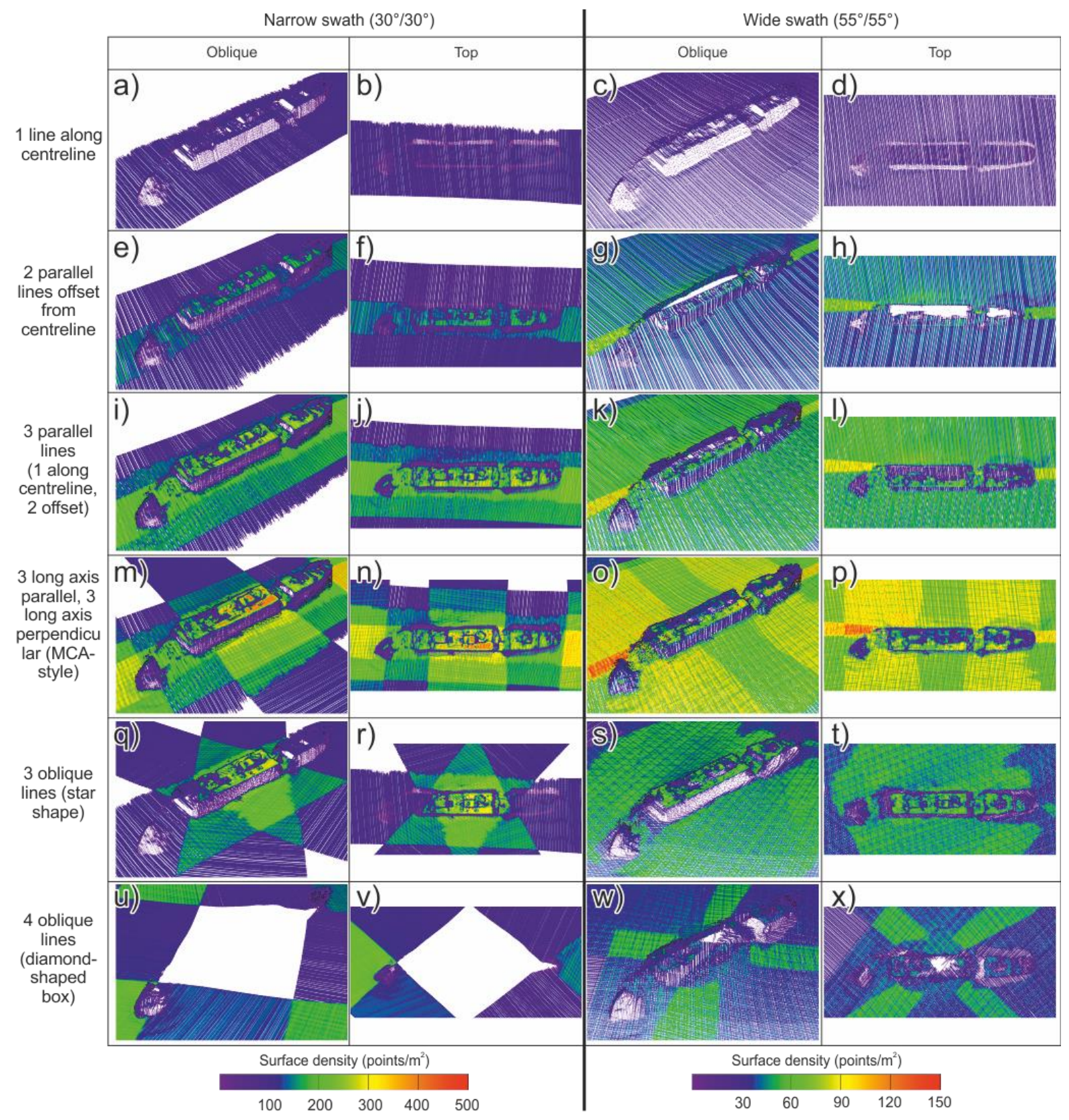

Fig. 8 Matrix of change in sounding surface density according to survey design using both narrow and wide swaths $\left(55^{\circ} / 55^{\circ}\right.$ vs $\left.30^{\circ} / 30^{\circ}\right)$. Note that the colour scale is re-scaled between the wide and narrow swath tests to account for the roughly threefold increase in surface density achieved by the latter 


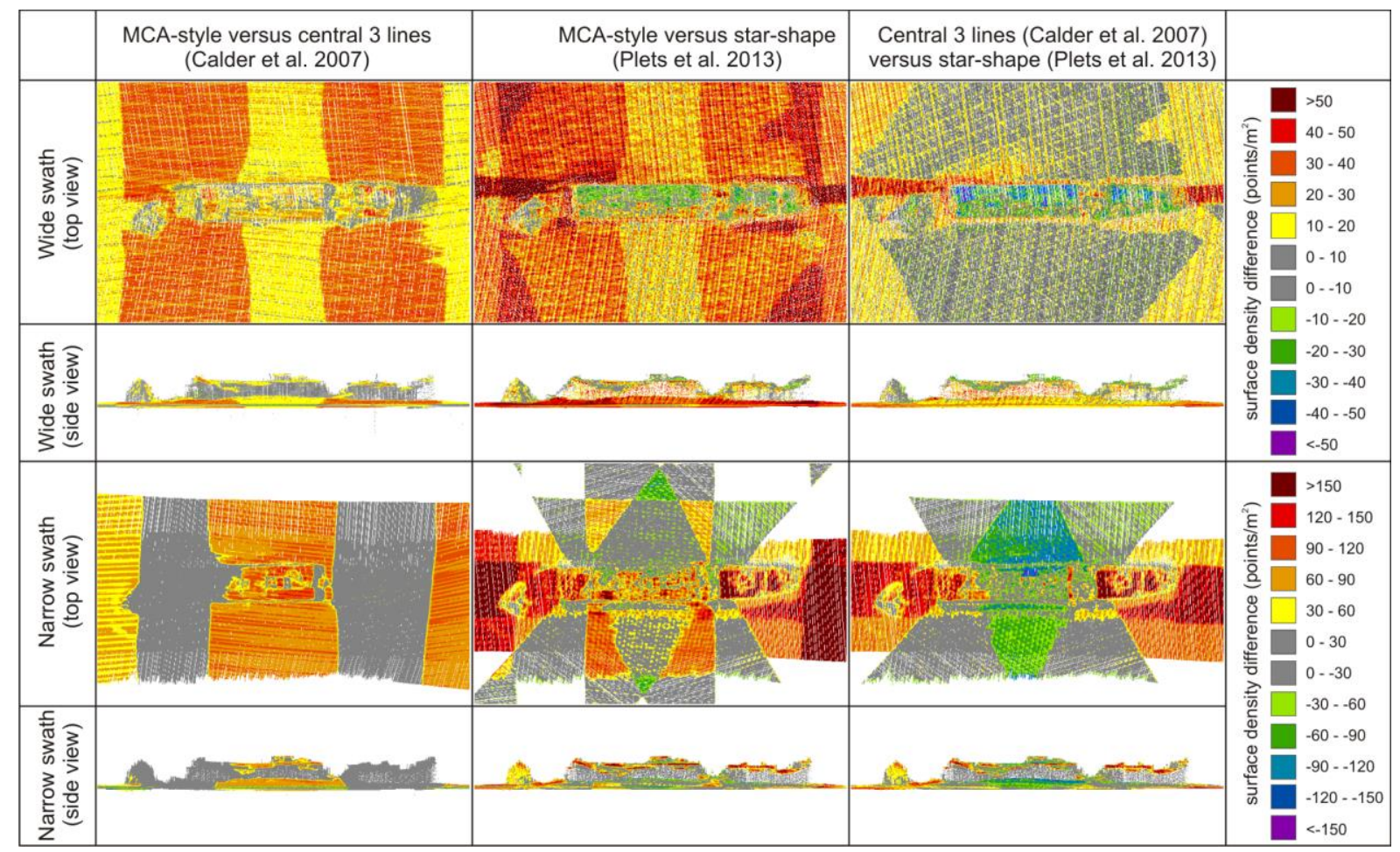

Fig. 9 Difference models comparing surface density on top and sides of wreck between previously published survey strategies (Calder et al. 2007; MCA 2013; Plets et al. 2013). In each case, the second survey strategy has been subtracted from the first. Warm colours indicate positive change (i.e. first strategy achieves higher surface density than the second); cold colours indicate negative change (i.e. first strategy achieves lower surface density than the second). Note that the colour scale is re-scaled between the wide and narrow swath tests to account for the roughly threefold increase in surface density achieved by the latter 


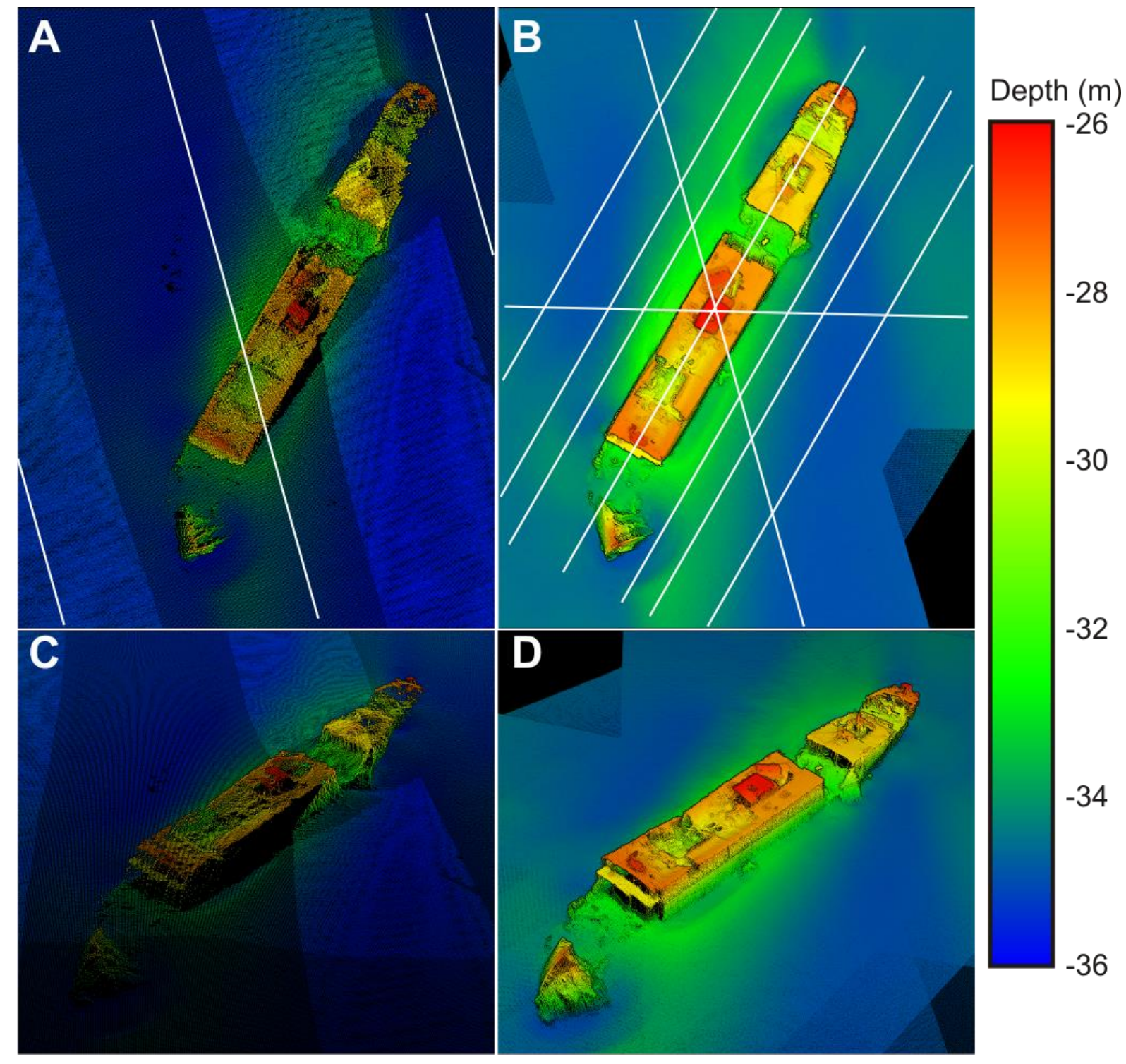

Fig. 10 Comparative images of SS Polwell based on cleaned and tidally-corrected standard density and HD point clouds. A) Top view, standard density cloud. B) Top view, HD cloud. C) Oblique view, standard density cloud. D) Oblique view, HD cloud. Survey lines used to acquire the data are superimposed in white on each of the top views. Standard density cloud was acquired by 3 oblique survey lines running NNW-SSE across the wreck using $55^{\circ} / 55^{\circ}$ (sector mode normal). HD cloud collected by 5 centreline parallel lines and 2 oblique lines crossing the centre (star-shape) at $30^{\circ} / 30^{\circ}$ (sector mode single) plus 2 wider offsets at $55^{\circ} / 55^{\circ}$ angular sector (sector mode normal) 


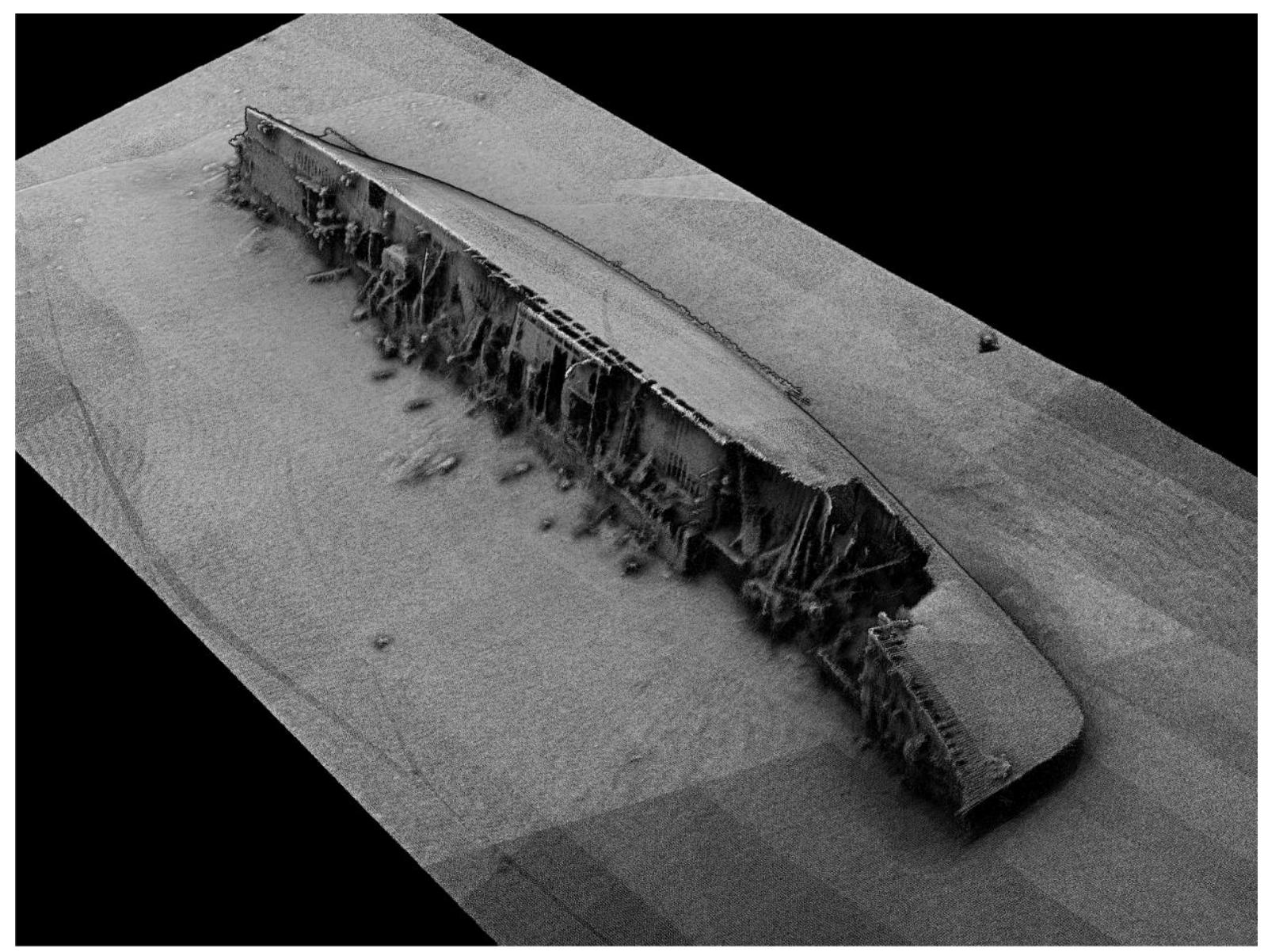

Fig. 11 HD point cloud of SS Chirripo, lost 1917 off Northern Ireland (20-25 m water depth). Image created from multiple passes and multiple directions at different angular sectors. Surface densities on the tilted deck range between $50-500$ points $/ \mathrm{m}^{2}$, while surface densities on the upwards-facing hull side range between $200-1000$ points $/ \mathrm{m}^{2}$ 